\title{
Primary Results of Late Surgical Treatment in Children with Tetralogy of Fallot from a Developing Country
}

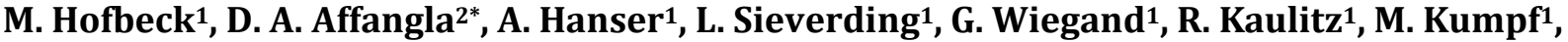 \\ M. Moustafi ${ }^{3}$, F. Neunhoeffer ${ }^{1}$, C. Schlensak ${ }^{3}$, G. A. Bazolo Ba Ngouala ${ }^{4}$, D. M. Ba ${ }^{2}$, I. Basse ${ }^{2}$, M. Leye ${ }^{2}$ \\ ${ }^{1}$ Department of Pediatric Cardiology, University Hospital of Tübingen, Tübingen, Germany \\ ${ }^{2}$ Faculty of Medicine, University of Thiès, Thiès, Senegal \\ ${ }^{3}$ Department of Thoracic and Cardiovascular Surgery, University Hospital of Tübingen, Tübingen, Germany \\ ${ }^{4}$ Louga Regional Hospital, Louga, Senegal \\ Email: *docalaf@gmail.com
}

How to cite this paper: Hofbeck, M., Affangla, D.A., Hanser, A., Sieverding, L., Wiegand, G., Kaulitz, R., Kumpf, M., Moustafi, M., Neunhoeffer, F., Schlensak, C., Ngouala, G.A.B.B., Ba, D.M., Basse, I. and Leye, M. (2019) Primary Results of Late Surgical Treatment in Children with Tetralogy of Fallot from a Developing Country. World Journal of Cardiovascular Diseases, 9, 538-544.

https://doi.org/10.4236/wjcd.2019.98046

Received: June 29, 2019

Accepted: August 10, 2019

Published: August 13, 2019

Copyright $\odot 2019$ by author(s) and Scientific Research Publishing Inc. This work is licensed under the Creative Commons Attribution International License (CC BY 4.0).

http://creativecommons.org/licenses/by/4.0/

\section{Open Access}

\begin{abstract}
Objectives: The purpose was to show how important is to operate on the Senegalese African children presenting with Tetralogy of Fallot (TOF) regardless of their age. Methods: It is a retrospective, descriptive analysis of data from the Department of Pediatric Cardiology, University Hospital of Tuebingen's data base which was searched for all cases of TOF in foreign patients younger than 15 years between 05/2004-10/2016. Results: 16 children from Senegal with TOF were referred for treatment. Mean age of patients was 7.0 years (range 0.9 - 14.8 years). Primary corrective surgery was performed in 13/16 patients. A primary shunt procedure was required in 3/16 patients. All patients were discharged in good condition with a median 13 postoperative days. We did not register any deaths. All became asymptomatic with pulse oximetry oxygen saturations greater than $95 \%$. The right ventricular outflow tract (RVOT) gradient was less than $30 \mathrm{mmHg}$ in all patients and 2 patients had moderate pulmonary valvular insufficiency. Conclusions: It was still necessary to operate Senegalese children presenting with TOF irrespective of their age.
\end{abstract}

\section{Keywords}

Tetralogy of Fallot, Late Repair, Developing Country, Non-Governmental Non-Profit Organization

\section{Introduction}

Primary repair of Tetralogy of Fallot (TOF) in the first year of life is the result of 
improvements in surgical techniques during the last decades [1] [2]. Advantages of early repair include preservation of myocardial function, avoidance of right ventricular hypertrophy and fibrosis, promotion of pulmonary artery growth and avoidance of cyanotic multi-organ damage. Treatment options in developing countries are frequently restricted due to limited availability of diagnostic and therapeutic facilities [3]. We report the results in a cohort of children in Senegal who were referred to our center for surgical treatment.

\section{Patients and Methods}

It is a retrospective, descriptive analysis from the database of the department of Pediatric Cardiology, University Hospital of Tüebingen. The database was searched for all cases of TOF in foreign patients younger than 15 years between 05/2004-10/2016.

The primary diagnosis having been established in Senegal by echocardiography was confirmed in Tübingen.

The following parameters were analyzed: diagnostic conformity, age, weight, dyspnea according to the NYHA classification, associated morbidities, type of surgery performed, length of hospital stay, and early postoperative outcomes.

\section{Results}

Sixteen children with TOF were referred for treatment in our center (Table 1) with a mean age of 7.0 years (range 0.9 - 14.8 years, median 5.5 years). Almost all patients were dystrophic with a mean BMI of 13.7 (range 9.8 - 16.7, median 13.5). All patients were significantly cyanosed and presented in NYHA class III IV. The mean oxygen saturation $(\mathrm{SpO} 2)$ was $62 \%($ range $35 \%-92 \%$, median $=$ $75 \%)$.

The diagnosis of TOF was established in the city of Thiès in all the cases, in conformity with the reference center of the hospital of Tübingen. Cardiac catheterization prior to the first surgical procedure was required in 3/16 patients. Primary corrective surgery was performed in $13 / 16$ patients. A valve sparing transatrial approach was performed in 10 patients (Figure 1, Figure 2). One of these patients required secondary transannular patch enlargement 2 days later. One patient, who presented with active endocarditis and vegetations on the aortic and pulmonary valve, underwent corrective surgery including aortic and pulmonary valve replacement (Figure 3). Corrective surgery with RVOT patch-enlargement was performed in a further 2 patients. A primary shunt procedure was required due to persistent hypoxemic spells necessitating treatment with noradrenalin in 2 patients (13.8 and 3.3 years) and excessive hypertrophy of both ventricles in 1 case (6.8 years). These patients underwent secondary corrective surgery requiring RVOT patch enlargement in one. All patients were discharged in good condition with a median 13 postoperative days.

We did not register any deaths and all patients returned to Senegal. All became asymptomatic with pulse oximetry oxygen saturations greater than $95 \%$. 
Table 1. Clinical, preoperative characteristics and type of surgery.

\begin{tabular}{|c|c|c|c|c|c|}
\hline Patient & $\begin{array}{l}\text { Age } \\
\text { (Year) }\end{array}$ & BMI & $\begin{array}{l}\text { Preoperative } \\
\text { morbidity }\end{array}$ & Cardiac surgery & $\begin{array}{c}\text { Discharge } \\
\text { (days post op) }\end{array}$ \\
\hline 1 & 13.3 & 12.6 & - & transatrial valve sparing corrective surgery & 26 \\
\hline 2 & 5.2 & 13.3 & - & transatrial valve sparing corrective surgery & 18 \\
\hline 3 & 9.6 & 12.7 & cerebral abscess & transatrial valve sparing corrective surgery & 10 \\
\hline 4 & 10.8 & 16.2 & - & corrective surgery, secondary RVOT patch & 25 \\
\hline 5 & 9.7 & 13.6 & - & corrective surgery, RVOT patch & 13 \\
\hline 6 & 4 & 16.7 & - & transatrial valve sparing corrective surgery & 8 \\
\hline 7 & 4.5 & 14.3 & - & transatrial valve sparing corrective surgery & 7 \\
\hline 8 & 5.7 & 9.8 & - & transatrial valve sparing corrective surgery & 11 \\
\hline 9 & 14.8 & 15.2 & endocarditis & corrective surgery, ao/pulm. valve replacement & 52 \\
\hline 10 & 2 & 12.1 & cerebral infarction & transatrial valve sparing corrective surgery & 7 \\
\hline 11 & 3.2 & 16.4 & cerebral infarction & transatrial valve sparing corrective surgery & 13 \\
\hline 12 & 5 & 12.7 & hypoxemic spells & transatrial valve sparing corrective surgery & 18 \\
\hline 13 & 0.9 & 16.6 & - & corrective surgery, RVOT patch & 13 \\
\hline \multirow{2}{*}{14} & 13.8 & 15.4 & hypoxemic spells & aortopulmonary shunt & 32 \\
\hline & 13.9 & 14 & - & transatrial valve sparing corrective surgery & 15 \\
\hline \multirow{2}{*}{15} & 3.3 & 12 & hypoxemic spells & right BTS $5 \mathrm{~mm}$ & 9 \\
\hline & 4.5 & 13.9 & - & corrective surgery, RVOT patch & 8 \\
\hline 16 & 6.8 & 9.8 & - & aortopulmonary shunt & 7 \\
\hline
\end{tabular}

BMI: Body Mass Index; RVOT: Right Ventricle Outflow Tract; BTS: Blalock-Taussig Shunt.

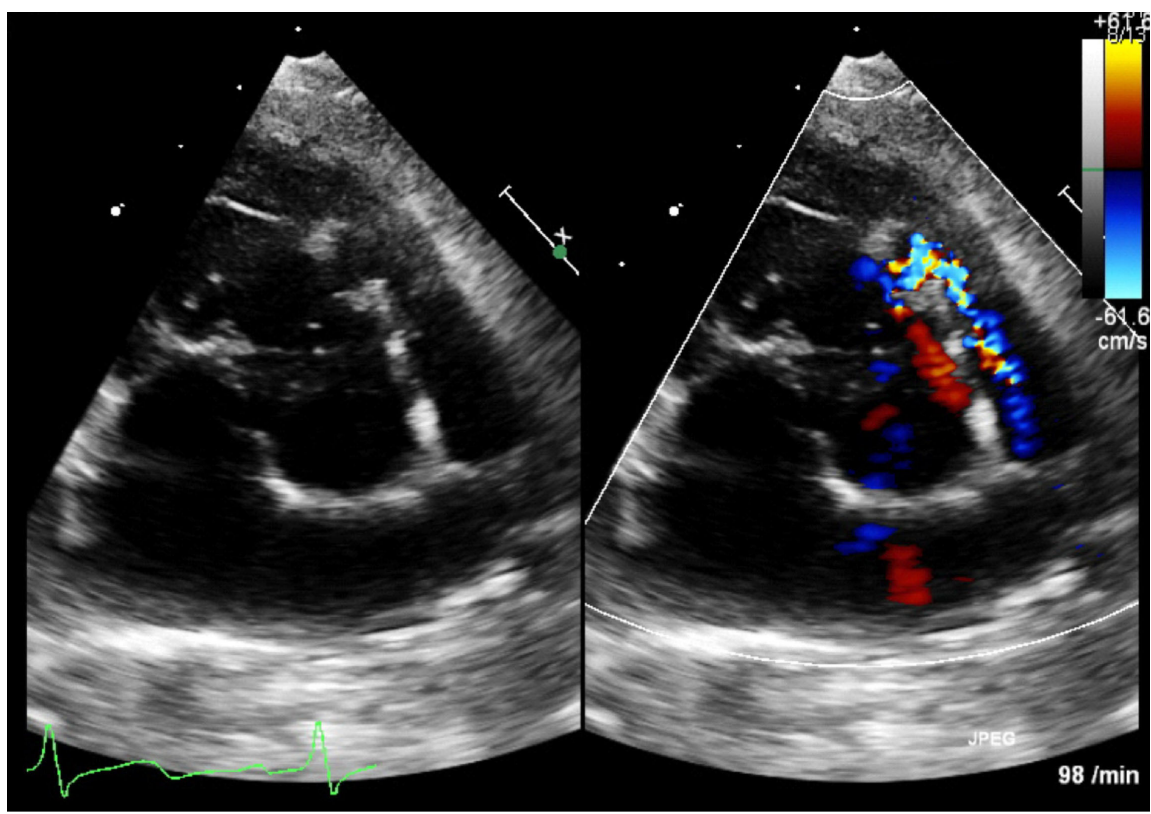

Figure 1. The parasternal short axis view in a 5.7 year old boy (patient 8 ) shows very severe right ventricular outflow tract obstruction at infundibular level, while the main pulmonary artery is of reasonable size. 


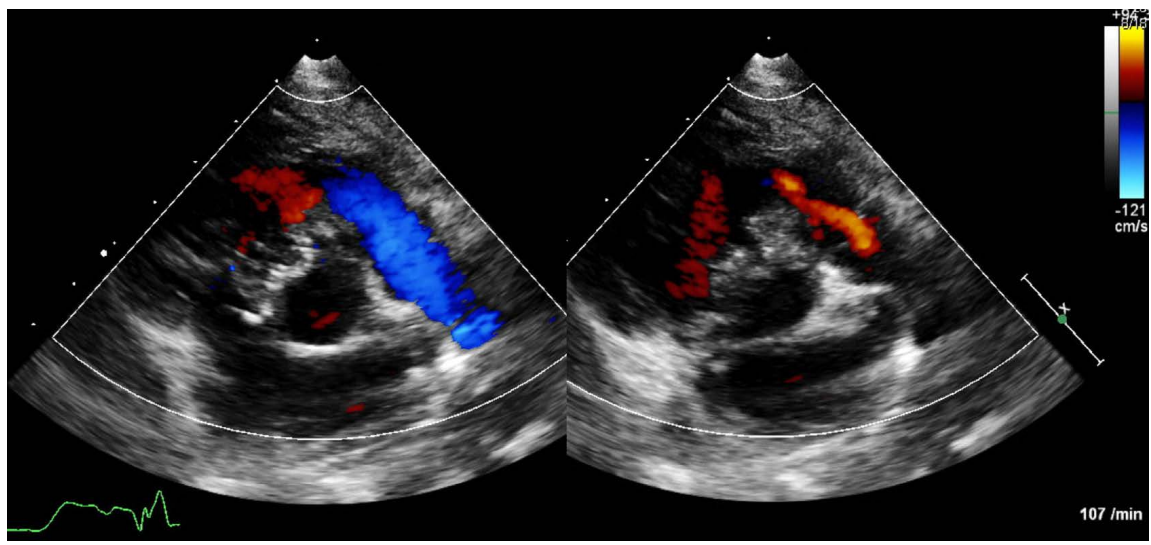

Figure 2. The postoperative parasternal short axis view (patient 8) following transatrial valve-sparing surgical repair shows no relevant residual gradient across the RVOT and only mild pulmonary regurgitation.

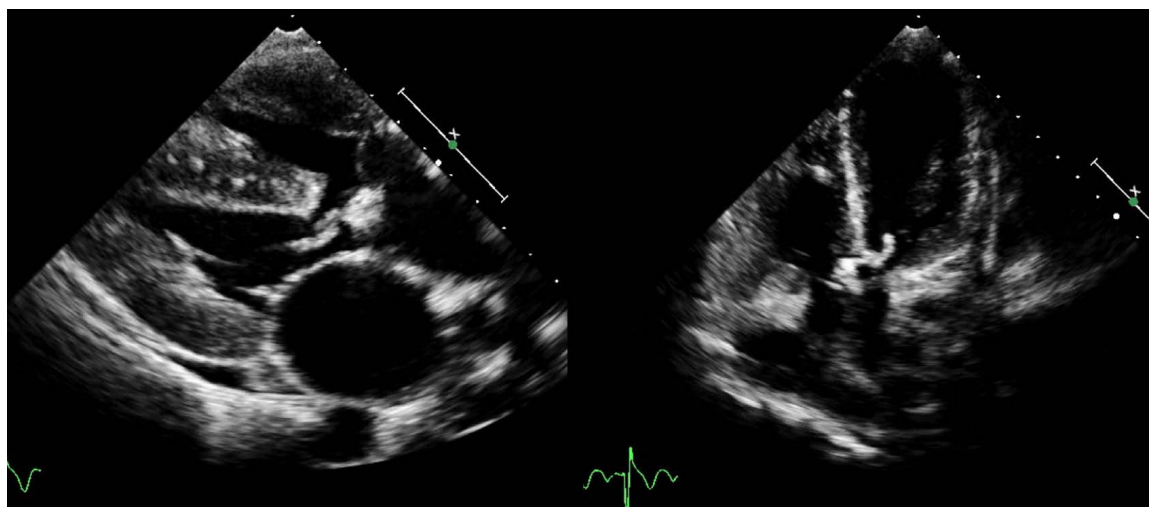

Figure 3. The parasternal long axis view in a 14.8 year old with bacterial endocarditis (pat. 9) shows the perimembranous malalignment VSD and a large vegetation on the overriding aortic valve. The vegetations of the aortic valve are also displayed on the diastolic frame in the apical 5 chamber view.

The right ventricular outflow tract (RVOT) gradient was less than $30 \mathrm{mmHg}$ in all patients and 2 patients had moderate pulmonary valvular insufficiency.

\section{Discussion}

Tetralogy of Fallot is one of the most frequent childhood heart diseases in Africa [4] [5] [6]. Its management, particularly surgical, contributes in the fight against infant mortality [5] [7]. The average age of our patients was 7 years (ranges 0.9 14.8 years) was about the same as that of other studies of African children operated on for TOF within Africa or elsewhere in the West. Beye in Dakar, Senegal [8] had an average age of 7.78 years (range, 0.6 to 19 years), Benbrink in Nantes, France [9] had a mean age of 4.8 years \pm 3.2 , and the mean age of patients in the Tchoumi series in Shisong, Cameroon [10] was slightly higher at $9.18 \pm 6.5$ years (range 1.12 and 26 years old). However, the ages of our patients are significantly higher than the ages 3 to 6 months recommended from the analysis of Western series [2]. 
The diagnosis criteria of TOF employed in Thiès was in all cases in conformity with that employed at the reference center of the hospital of Tübingen, thus confirming the availability of human resources competent in the diagnosis of congenital heart disease in the rural areas of Senegal. The Cardiac Doppler ultrasound is the gold standard in the diagnosis of TOF. However, cardiac catheterization preoperatively to better appreciate the anatomy of the coronary arteries, pulmonary artery and its branches was performed in 3/16 of our patients. Tchoumi, J.C.T. [10] also performed it in $3 / 22$ patients.

An oxygen saturation of less than $95 \%$ on routine pulse oximetry screening within 24 hours after birth may be an interesting alternative for the diagnosis of severe congenital heart disease in newborns [11].

Despite late referral with the mean age at 7 years, severe obstruction of the RVOT and pronounced cyanosis, surgery for TOF was possible with low mortality. Primary surgical repair with preservation of the pulmonary valve was performed in the majority of our patients avoiding the long term sequelae of patch enlargement of the RVOT and significant pulmonary regurgitation. Primary palliative procedures were required only in $3 / 16$ patients with persistent hypoxemic spells and excessive RV hypertrophy.

The complications observed in the preoperative period of our patients were more than those found by Benbrink and Tchoumi [9] [10]. These included infectious endocarditis (1 case), cerebral abscess (1 case), cerebral infarction (1 case) and biventricular hypertrophy (1 case). Benbrink reported extensive aortic-pulmonary collaterals in 2 children with severe diffuse hypoplasia of the pulmonary artery and impaired left ventricular systolic function. In the western series, these complications are absent thus justifying the advantages of the early surgery [2].

The mean duration of hospitalization was $15 \pm 7$ days. This period of hospitalization is similar to that found by Benbrink and Tchoumi [9] [10] who found 11 \pm 6 days and $15 \pm 7$ days respectively. None of the patients in our series died. Benbrink reports a death of 2 out of 47 patients (4.2\%). It should be noted, however, that the number of patients was greater than in our series. But this mortality was not significantly higher than in the group of French patients operated at an earlier age. Tchoumi, J.C.T. [10] noted early postoperative mortality in $2 / 22$ patients (9\%).

The results are also equally satisfactory in view of the regression of dyspnea in all patients, the improvement of $\mathrm{Sp} 02$ and the low residual gradient on the RVOT. However, long-term follow-up will be necessary especially in patients in whom a patch enlargement for RVOT was performed [12].

\section{Conclusion}

The unfavorable natural history and the disabling sequelae of chronic hypoxemia justify all efforts to attempt late corrective surgery in children with TOF. While waiting for the local development of the pediatric cardiac surgery, the 
nongovernmental non-profit humanitarian organization plays an important role.

\section{Acknowledgements}

Data collection was realized under consideration of confidential aspects.

Funding for treatment was provided by a non-governmental non-profit organization and we are grateful to Mrs Christel Fritschi and the non-governmental non-profit organization Bilbassi.

\section{Limitation}

Small sample size in our series.

\section{Conflicts of Interest}

The authors declare no conflicts of interest regarding the publication of this paper.

\section{References}

[1] Castaneda, A.R., Lamberti, J., Sade, R.M., Williams, R.G. and Nadas, A.S. (1974) Open-Heart Surgery during the First Three Months of Life. The Journal of Thoracic and Cardiovascular Surgery, 68, 719-731.

[2] Steiner, M.B., Tang, X., Gossett, J.M., Malik, S. and Prodhan, P. (2014) Timing of Complete Repair of Non-Ductal Dependent Tetralogy of Fallot and Short-Term Postoperative Outcomes, a Multicenter Analysis. The Journal of Thoracic and Cardiovascular Surgery, 147, 1299-1305. https://doi.org/10.1016/j.jtcvs.2013.06.019

[3] Mocumbi, A.O., Lameira, E., Yaksh, A., Paul, L., Ferreira, M.B. and Sidi, D. (2011) Challenges on the Management of Congenital Heart Disease in Developing Countries. International Journal of Cardiology, 148, 285-288. https://doi.org/10.1016/j.ijcard.2009.11.006

[4] Bazolo Ba Ngouala, G.A., Affangla, D.A., Leye, M. and Kane, A. (2015) Prevalence des cardiopathies infantiles symptomatiques au Centre Hospitalier Régional de Louga, Sénégal. Cardiovascular Journal of Africa, 26, e1-e5. https://doi.org/10.5830/CVJA-2015-031

[5] Deloche, A., Babatasi, G., Baron, O., Roux, D., Chauvaud, S., Sidi, D. and Vouhe, P. (2011) La chirurgie cardiaque pédiatrique dans les pays en voie de developpement. Vingt ans d'experience de la Chaine de l'Espoir. Bulletin de 1 Academie Nationale de Medecine, 195, 305-308. https://doi.org/10.1016/S0001-4079(19)32088-6

[6] Affangla, D.A., Bazolo, G.A., Leye, M., Aw, F. and Kane, A. (2014) Prise en charge des cardiopathies infantiles. A propos de 43 enfants diagnostiqués à Thiès (Sénégal) et opérés. Médecine d Afrique Noire, 61, 202-212.

[7] M'pembaLoufoua-Lemay, A.B. and Massamba, A. (2016) Epidemiology of Cardiovascular Diseases in Children at the Teaching Hospital of Brazzaville, Congo. World Journal of Cardiovascular Diseases, 6, 410-424. https://doi.org/10.4236/wjcd.2016.611045

[8] Beye, S.A., Fall, L., Ciss, G., Diarra, O., NDiaye, M., Ba, P.S., Cissé, G., Ndiaye, A., Kane, O., Diop, I.B., Sall, K.B. and NDiaye, M. (2009) Anesthesie-Reanimation dans la cure complète des cardiopathies congenitales au Sénégal au CHNU de fann. Mali Médical, 24, 47-50. 
[9] Benbrink, N., Romefort, B., Le Gloan, L., Warin, K., Hauet, Q., Guerin, P., Baron, O. and Gournay, V. (2015) Late Repair of Tetralogy of Fallot during Childhood in Patients from Developing Countries. European Journal of Cardio-Thoracic Surgery, 47, e113-e117. https://doi.org/10.1093/ejcts/ezu469

[10] Tchoumi, J.C.T., Ambassa, J.C., Giamberti, A., Cirri, S., Frigiola, A. and Butera, G. (2008) Late Surgical Treatment of Tetralogy of Fallot. Cardiovascular Journal of Africa, 22, 179-181. https://doi.org/10.5830/CVJA-2010-057

[11] Ewer, A.K., Furmston, A.T., Middleton, L.J., Deeks, J.J., Daniels, J.P., Pattison, H.M., et al. (2012) Pulse Oximetry as a Screening Test for Congenital Heart Defects in Newborn Infants: A Test Accuracy Study with Evaluation of Acceptability and Cost-Effectiveness. Health Technology Assessment, 16, 1-184.

https://doi.org/10.3310/hta16020

[12] Dupuis, C., Kachaner, J., Robert, M., Payot, F.M. and Davignon, A. (1991) Tétralogie de Fallot. In: Cardiologie pédiatrique, 2nd Edition, Médecine-Science Flammarion, Paris, 327-346. 